\title{
SELECTIVE ELECTROEXTRACTION OF BASE METALS FROM LEACHING SOLUTIONS OBTAINED DURING THE RECYCLING OF WASTE PRINTED CIRCUIT BOARDS. II. SELECTIVE POTENTIOSTATIC ELECTRODEPOSITION OF COPPER, TIN AND LEAD
}

\author{
MARIAN-IOSIF FRÎNCUa, ENIKO COVACI ${ }^{a}$, \\ SORIN-AUREL DORNEANU ${ }^{\mathrm{a}, \mathrm{b},{ }^{*}, \text { PETRU ILEA }}{ }^{\mathrm{a}, \mathrm{b}}$
}

\begin{abstract}
This paper presents our results concerning the feasibility of selective potentiostatic electroextraction of copper, tin and lead from leaching solutions obtained during the recycling of base metals from waste printed circuit boards. Applying this protocol, in a first stage, the concentration of $\mathrm{Cu}$ ions from the leaching solutions can be lowered, with acceptable efficiency, below $0.5 \mathrm{~g} / \mathrm{L}$. To avoid the contamination of $\mathrm{Sn}-\mathrm{Pb}$ alloys with $\mathrm{Cu}$, an intermediary step of Cu cementation on metallic Sn were proposed and tested. Finally, the potentiostatic selective electrodeposition protocol was successfully applied for the electroextraction $\mathrm{Sn}-\mathrm{Pb}$ alloys. The experiments were performed in real leaching samples, using a Fisher type electrode as cathode. The obtained experimental results demonstrate that, controlling rigorously the imposed potential and corelating them with the solution composition, high purity $\mathrm{Cu}$ and $\mathrm{Sn}-\mathrm{Pb}$ alloys deposits can be obtained, maximum contents of $99.96 \%, 99.83 \%$ and $82.62 \%$ being evaluated for $\mathrm{Cu}$, $\mathrm{Sn}$ and $\mathrm{Pb}$, respectively.
\end{abstract}

Keywords: waste printed circuit boards, potentiostatic selective electroextraction, copper recovery, tin and lead alloy electrodeposition.

\section{INTRODUCTION}

It is well known that, due to the depletion of mineral resources, the use of different wastes as secondary resources gains increased attention.

a Babeş-Bolyai University, Faculty of Chemistry and Chemical Engineering, Department of Chemical Engineering, 11 Arany Janos Street, Cluj Napoca, RO-400028, Romania

b Babeş-Bolyai University, Interdisciplinary Research Institute on Bio Nano Sciences, 42 Treboniu Laurian Street, Cluj Napoca, RO-400271, Romania

*Corresponding author: sorin.dorneanu@ubbcluj.ro 
Currently, consistent researches concerning the recycling of secondary resources are focused on the wasted printed circuit boards (WPCBs) [1], which are the base of the electronics industry. The WPCBs present a potentially high economic value, a serious concern for the environment [2], and an emerging trend towards the circular economy [3].

Copper is the major metal found in WPCBs and its recovery is therefore a top priority [4], followed by tin, lead and other metals [5]. From the ecological and economic point of view, the electrochemical recovery of metals from WPCBs presents significant advantages [6,7], it can apply highly efficient strategies [8] like the electroextraction one [9] or more complex processes $[10,11]$, many of them based on the selective electrodeposition [12,13].

The cathodic electrodeposition represents an efficient method for the electrochemical recovery of the metals from a solution [14], extensive studies presenting different strategies and efficiencies for the Cu electroextraction [15] or the $\mathrm{Sn}-\mathrm{Pb}$ alloys deposition $[16,17]$, processes that are constantly improved [18]. Electrochemical deposition was used to obtain thin films of $\mathrm{Cu}$ and Sn$\mathrm{Pb}$ alloy [19] which have wide applications in the industrial revolution. Starting from the results obtained during our previous research [13,20,21], this paper aimed to evaluate the feasibility of potentiostatic selective electroextraction of copper and $\mathrm{Sn}-\mathrm{Pb}$ alloys from solutions resulting during the recovery of base metals from WPCBs using the leaching system $\mathrm{KBr} / \mathrm{HBr} / \mathrm{Br}_{2}$. Based on the literature data [22], to prevent the contamination of electrodeposited $\mathrm{Sn}-\mathrm{Pb}$ alloys with $\mathrm{Cu}$, an intermediary step of $\mathrm{Cu}$ cementation on metallic $\mathrm{Sn}$ were also proposed and tested. For an accurate evaluation of process efficiency, the experiments were divided in several short time tests, the weight and the composition of the intermediary obtained deposits being evaluated. For these steps, the deposits were washed, dried, and detached from the Fisher type working electrode (WE) by mineralization with aqua-regia and analyzed by flame atomic absorption spectroscopy (FAAS) and inductively coupled plasma atomic emission spectroscopy (ICP-AES).

\section{RESULTS AND DISCUSSION}

\section{The selective potentiostatic electrodeposition of $\mathrm{Cu}$}

Our previous results concerning the intense and fast selective electrodeposition of $\mathrm{Cu}$ from the leaching solutions demonstrated that high purity $\mathrm{Cu}$ deposits can be obtained, in parallel with the regeneration of the leaching solution, at high current densities [13] if the concentration of $\mathrm{Cu}$ ions remains over $12 \mathrm{~g} / \mathrm{L}$. Continuing the previous work, in the present paper, we 
proposed and tested a new protocol for the selective potentiostatic electroextraction of several metals $(\mathrm{Cu}, \mathrm{Sn}$ and $\mathrm{Pb})$. The main goal of the research was to evaluate the feasibility of the complete extraction of these metals from the leaching solutions.

Based on the information obtained by cyclic voltammetry and galvanostatic electrodeposition, the tests concerning the selective potentiostatic electroextraction of $\mathrm{Cu}$ from the leaching solutions started at imposed working electrode potentials ( $\left.E_{W E}\right)$ of $-0.25 \mathrm{~V}$ vs. the reference electrode (RE) [13]. As detailed in the experimental section, the initial concentration of the $\mathrm{Cu}$ ions in the real leaching solution sample was $12.89 \mathrm{~g} / \mathrm{L}$. When the recorded current through the WE (IWE) decreased at 10\% from the initial value, the experiment was stopped and the Fisher type WE was removed from the electrochemical cell, washed, dried and weighted. The obtained deposits were detached from the WE by mineralization with aqua-regia and the obtained solutions were analyzed by FAAS and ICP-AES to evaluate its composition. An example of images corresponding to the cleaned Fisher type electrode and of a $\mathrm{Cu}$ deposit obtained by electroextraction are presented in Figure 1.A and 1.B, respectively.

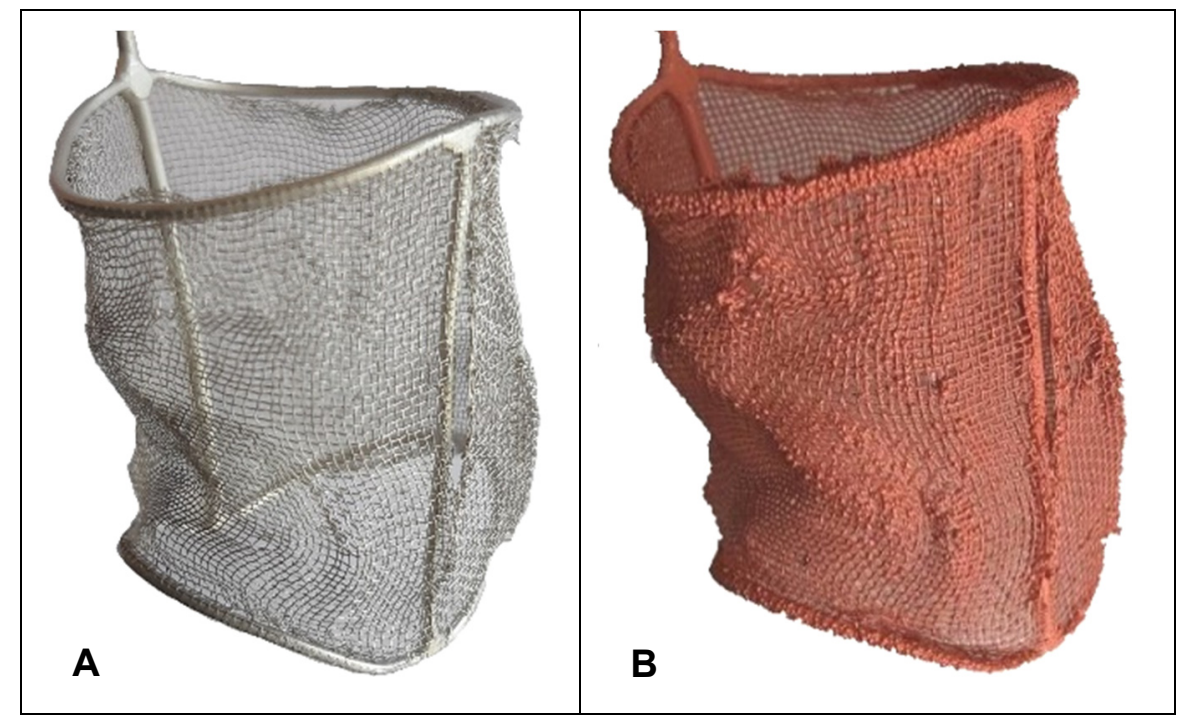

Figure 1. Example of images of the clean Fisher type electrode $(A)$ and of the copper deposit obtained after electrodeposition (B).

Afterwards, the imposed EWE was progressively switched to more negative values of -0.3 and $-0.35 \mathrm{~V} / \mathrm{RE}$ The main electrical parameters recorded during the selective potentiostatic electrodeposition of $\mathrm{Cu}$ are 
presented in Figure 2, where $\mathrm{U}_{\mathrm{T}}, \mathrm{E}_{\mathrm{CE}}, \mathrm{pH}$ and $\mathrm{ORP}$ represent the instantaneous values of the voltage at the electrochemical cell terminals, counter electrode (CE) potential, $\mathrm{pH}$ and oxidation/reduction potential, respectively. Also, the mean and/or individual values of the operational and efficiency parameters evaluated from the experimental data are presented in Table 1, were $\mathrm{C}_{\mathrm{EF}}$ and $W_{S}$ represent the current efficiency and the specific electricity consumption, and $E_{W E, M}, I_{W E, M}$ and $O_{R P}$ represent the average values of $E_{W E}$, IWE and ORP, respectively. [Cu] stands for the $\mathrm{Cu}$ ions concentration in the leaching solutions.

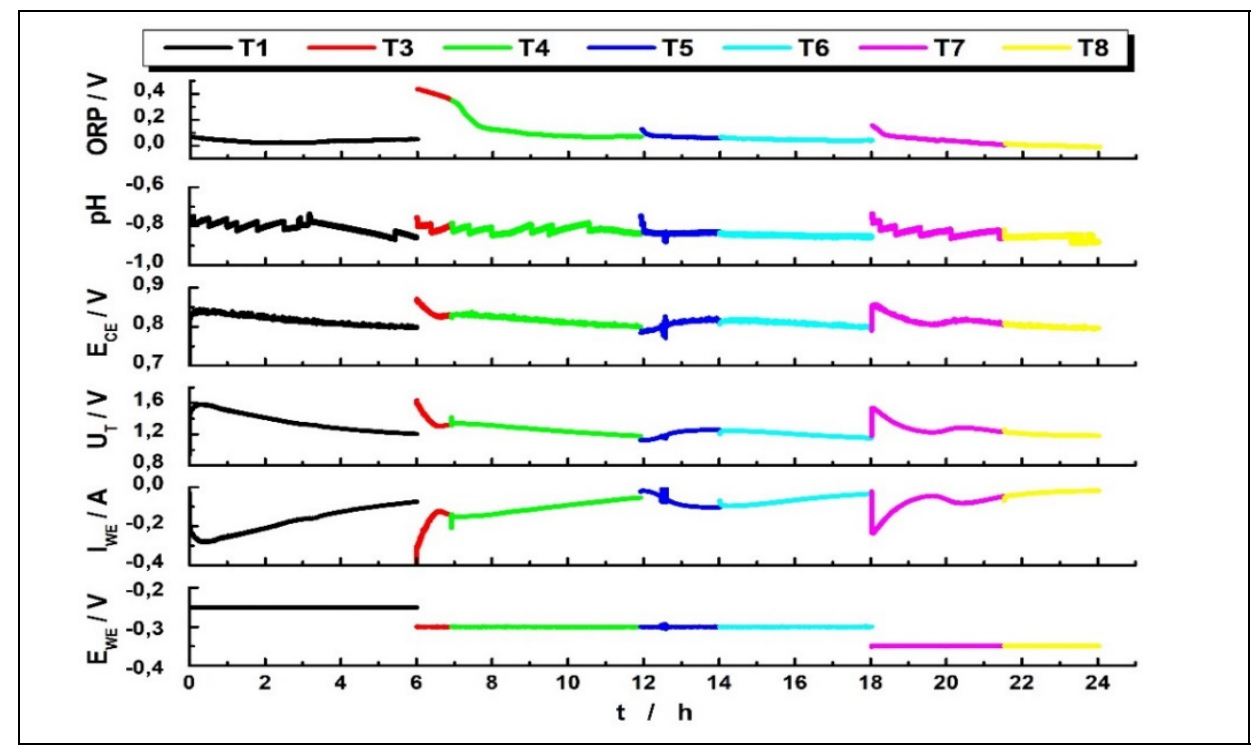

Figure 2. The evolution of the electrochemical and electrical parameters during the potentiostatic selective electrodeposition of $\mathrm{Cu}$ from the leaching solution.

Table 1. The evolution of the operational and efficiency parameters for the tests of potentiostatic selective electrodeposition of $\mathrm{Cu}$ from real leaching solutions.

\begin{tabular}{|c|c|c|c|c|c|c|c|c|}
\hline Deposit & Test & $\begin{array}{c}\text { EWE, M } \\
\text { (V/RE) }\end{array}$ & $\begin{array}{c}\text { IwE, M } \\
\text { (mA) }\end{array}$ & $\begin{array}{c}\mathbf{t} \\
\text { (min.) }\end{array}$ & $\begin{array}{c}{[\mathbf{C u}]} \\
\mathbf{( g / L )}\end{array}$ & $\begin{array}{c}\mathbf{C}_{\mathrm{EF}} \\
\mathbf{( \% )}\end{array}$ & $\begin{array}{c}\mathbf{W} \mathbf{s} \\
\text { (kWh/kg) }\end{array}$ & $\begin{array}{c}\text { ORPM } \\
\text { (V/RE) }\end{array}$ \\
\hline D1 & T1 & -0.25 & -172 & 361 & 5.17 & 95.9 & 0.62 & 0.038 \\
\hline D2 & T2 & -0.25 & -1.5 & 360 & 5.17 & 48.6 & 1.09 & 0.125 \\
\hline D3 & T3 & -0.30 & -173 & 55 & 1.63 & 65.7 & 0.84 & 0.397 \\
\hline D3 & T4 & -0.30 & -106 & 300 & 1.63 & 65.7 & 0.84 & 0.111 \\
\hline D4 & T5 & -0.30 & -74 & 126 & 1.58 & 1.7 & 30.46 & 0.071 \\
\hline D4 & T6 & -0.30 & -67 & 241 & 1.58 & 1.7 & 30.46 & 0.048 \\
\hline D5 & T7 & -0.35 & -86 & 211 & 0.36 & 41.9 & 1.32 & 0.049 \\
\hline D5 & T8 & -0.35 & -28 & 150 & 0.36 & 41.9 & 1.32 & 0.001 \\
\hline
\end{tabular}


As it can be seen in Figure 2, the $\mathrm{U}_{\mathrm{T}}, \mathrm{E}_{\mathrm{CE}}, \mathrm{pH}$ and $\mathrm{ORP}$ values remains relatively constant, proving the stability of the electrochemical system during the progressive $\mathrm{Cu}$ electroextraction. Contrarily, to maintain a reasonable high value of the IWE, and, consequently, an acceptable rate of Cu electroextraction, the imposed EWE value must be permanently adjusted to more and more negative values, in accordance with the decrease of the $\mathrm{Cu}$ ions concentration in the solutions. Otherwise, the reaction of hydrogen evolution (RHE) becomes the main process, wasting electrical energy without any supplementary electroextraction of $\mathrm{Cu}$. These conclusions are in excellent agreement with the $\mathrm{C}_{\mathrm{EF}}$ and $\mathrm{W}_{\mathrm{S}}$ values presented in Table 1.

Finally, it is worth to note that the concentration of the $\mathrm{Cu}$ ions in the leaching solution sample decreased from its initial value $(12.89 \mathrm{~g} / \mathrm{L})$ up to $0.36 \mathrm{~g} / \mathrm{L}$, proving the proposed process feasibility. The attempt to continue the process under this value leads to the enhancement of the RHE and increase the risk of $\mathrm{Sn}$ and $\mathrm{Pb}$ inclusion in the $\mathrm{Cu}$ deposits.

For the $\mathrm{Cu}$ obtained deposits, their compositions were evaluated analyzing the solution (resulting by mineralization of deposits with aquaregia) by FAAS, the obtained results being presented in Table 2.

Table 2. Percentage of metals (w/w) evaluated by FAAS in the deposits obtained by selective potentiostatic electrodeposition of $\mathrm{Cu}$ from the leaching solution.

\begin{tabular}{|c|c|c|c|c|c|c|}
\hline Test & Cu (\%) & Sn (\%) & Pb (\%) & Fe (\%) & Ni (\%) & Zn (\%) \\
\hline T1 & 99.78 & 0.22 & ND & 0.00 & ND & 0.00 \\
\hline T3+T4 & 99.91 & 0.00 & ND & 0.01 & ND & 0.00 \\
\hline T5+T6 & 98.76 & ND & ND & 0.90 & ND & 0.34 \\
\hline T7+T8 & 99.96 & 0.00 & ND & 0.04 & ND & 0.00 \\
\hline
\end{tabular}

The data presented in Table 2 reveal that the average purity of the deposits exceeds $99.8 \%$, proving that the selective potentiostatic electrodeposition of $\mathrm{Cu}$ from the leaching solution is a feasible and costeffective technology, leading to products of excellent quality and value.

\section{Extraction of $\mathrm{Cu}$ traces by cementation on metallic $\mathrm{Sn}$}

To recover completely the existing Cu from the leaching solutions and to avoid the contamination of the $\mathrm{Sn}-\mathrm{Pb}$ alloys deposit with $\mathrm{Cu}$ traces, we decided to implement a step of Cu cementation on metallic Sn between the $\mathrm{Cu}$ electrodeposition step and the $\mathrm{Sn}-\mathrm{Pb}$ alloys electroextraction stage. At this level, in the low $\mathrm{pH}$ values, the next reaction takes place:

$$
2 \mathrm{Cu}^{+}{ }_{(\mathrm{aq})}+\mathrm{Sn}^{0}{ }_{(\mathrm{s})} \rightarrow 2 \mathrm{Cu}^{0}{ }_{(\mathrm{s})}+\mathrm{Sn}^{2+}{ }_{(\mathrm{aq})}
$$


The variation of the measured parameters is presented in Figure 3.

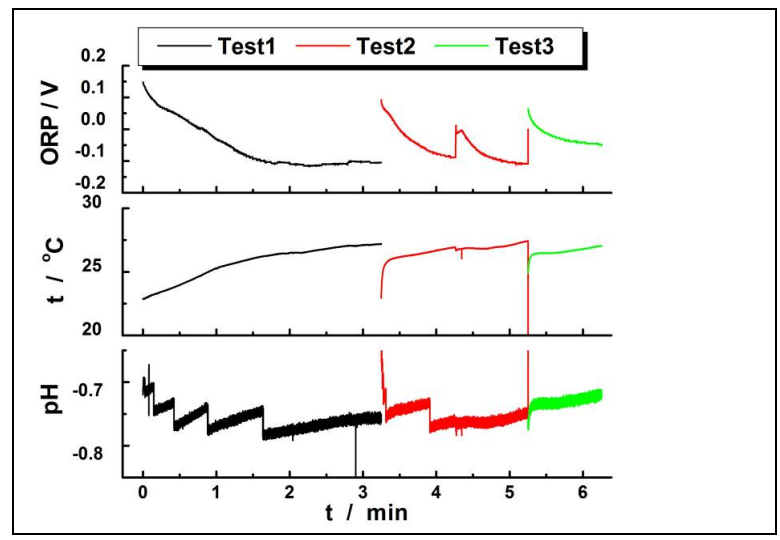

Figure 3. Evolution of $\mathrm{pH}$, temperature and ORP of the leaching solution during $\mathrm{Cu}$ cementation on metallic Sn.

During the cementation tests, samples were collected periodically from the chemical reactor and analyzed by FAAS. The evolution of the [Cu] values during this process is presented in Table 3.

Table 3. Evolution of [Cu] during the process of Cu cementation on metallic Sn.

\begin{tabular}{|c|c|c|c|c|c|c|c|}
\hline Time (h) & $\mathbf{0}$ & $\mathbf{1}$ & $\mathbf{2}$ & $\mathbf{3}$ & $\mathbf{4}$ & $\mathbf{5}$ & $\mathbf{6}$ \\
\hline [Cu] (mg/L) & 266.5 & 177.7 & 70.8 & 57.2 & 38.5 & 35.5 & 7.98 \\
\hline
\end{tabular}

Based on data presented in Figure 3 and Table 3, we demonstrated that the cementation of $\mathrm{Cu}$ traces using metallic $\mathrm{Sn}$ granules is a feasible, cost-effective, and efficient method to reduce significantly the [Cu] value. Practically, after 6 hours, the [Cu] was diminished from $\sim 250 \mathrm{mg} / \mathrm{L}$ to less than $8 \mathrm{mg} / \mathrm{L}$, without altering the $\mathrm{pH}$ or the ORP of the leaching solution.

\section{Selective potentiostatic electroextraction of $\mathrm{Sn}-\mathrm{Pb}$ alloys}

The measurements performed by cyclic voltammetry revealed that the electrodeposition of $\mathrm{Sn}$ and $\mathrm{Pb}$ begins at remarkably close potentials, around -0.5 and $-0.55 \mathrm{~V} / \mathrm{RE}$, and depends essentially on the concentration of these ions. Consequently, the selective electrodeposition of $\mathrm{Sn}$ and $\mathrm{Pb}$ is, practically, impossible, but the deposition of the $\mathrm{Sn}-\mathrm{Pb}$ alloys is favorized.

The electrochemical and electrical parameters recorded during the potentiostatic electrodeposition of $\mathrm{Sn}-\mathrm{Pb}$ alloys are presented in Figure 4. 


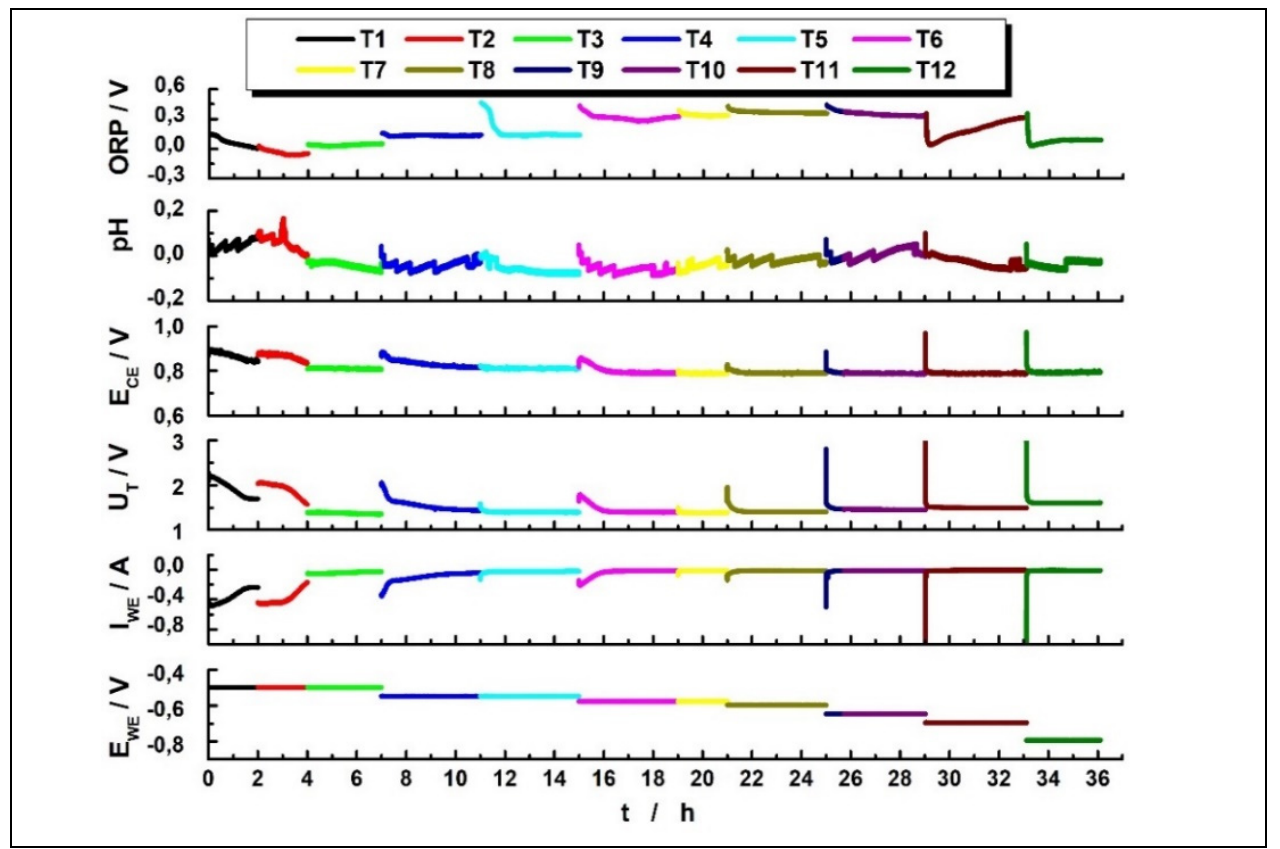

Figure 4. Evolution of electrochemical and electrical parameters during the tests of $\mathrm{Sn}-\mathrm{Pb}$ alloys electrodeposition from the leaching solution free of $\mathrm{Cu}$ ions.

As it can see from Figure 4, the measurements were performed at a starting $E_{W E}$ value of $-0.50 \mathrm{~V} / \mathrm{RE}$, and initial concentrations of $\mathrm{Sn}([\mathrm{Sn}])$ and $\mathrm{Pb}([\mathrm{Pb}])$ of 7.9 and $3.97 \mathrm{~g} / \mathrm{L}$, respectively. Further, the $E_{W E}$ values were shifted progressively, in correlation with the decrease of $[\mathrm{Sn}]$ and $[\mathrm{Pb}]$ values concentrations, to more negative values of $-0.55,-0.58,-0.6,-0.65,-0.7$ and, finally, of $-0.8 \mathrm{~V} / \mathrm{RE}$. As in the case of Cu electrodeposition, the modification of the applied $E_{W E}$ value was made when the instant IWE values decrease to $10 \%$ from the initial ones. In addition, the averaged and/or individual values of the operational and efficiency parameters were evaluated based on the experimental data, the obtained results being presented in Table 4.

Supplementary, Figure 4 reveals that the $U_{T}, E_{C E}$ and $p H$ values remains relatively constant, proving that the progressive electroextraction of $\mathrm{Sn}$ and $\mathrm{Pb}$ from the leaching solution do not affect the other proprieties of the electrochemical system. Contrarily, to maintain IWE at reasonable high value, the imposed $E_{W E}$ value must be permanently adjusted to more and more 
negative values, simultaneously with the decrease of the [Sn] and [Pb] values. Preserving the same $E_{W E}$ for a long period leads to the enhancing of the RHE process, affecting seriously the $\mathrm{C}_{\mathrm{EF}}$ and $\mathrm{W}_{\mathrm{S}}$ values.

Table 4. The evolution of the operational and efficiency parameters evaluated for the tests of potentiostatic selective electrodeposition of $\mathrm{Sn}-\mathrm{Pb}$ alloys from real leaching solutions with low $\mathrm{Cu}$ content.

\begin{tabular}{|c|c|c|c|c|c|c|c|c|c|}
\hline Deposit & Test & $\begin{array}{c}\text { EWE, } \mathbf{M} \\
\text { (V/RE) }\end{array}$ & $\begin{array}{c}\mathbf{t} \\
\text { (min.) }\end{array}$ & $\begin{array}{c}\text { [Sn] } \\
\text { (g/L) }\end{array}$ & $\begin{array}{c}\text { [Pb] } \\
\text { (g/L) }\end{array}$ & $\begin{array}{c}\mathbf{C}_{\mathrm{EF}} \\
\text { (\%) }\end{array}$ & $\begin{array}{c}\mathbf{W} \mathbf{s} \\
\text { (kWh/kg) }\end{array}$ & $\begin{array}{c}\text { IWE,M } \\
\text { (mA) }\end{array}$ & $\begin{array}{c}\text { ORPM } \\
\text { (V/RE) }\end{array}$ \\
\hline D1 & T1 & -0.50 & 120 & 2.95 & 3.97 & 45.54 & 1.93 & -353 & 0.065 \\
\hline D1 & T2 & -0.50 & 120 & 2.95 & 3.97 & 45.54 & 1.93 & -384 & 0.038 \\
\hline D2 & T3 & -0.50 & 180 & 2.53 & 3.97 & 47.06 & 1.30 & -41 & 0.039 \\
\hline D3 & T4 & -0.55 & 240 & 0.55 & 2.58 & 94.45 & 0.81 & -100 & 0.134 \\
\hline D4 & T5 & -0.55 & 240 & 0.51 & 2.54 & 8.85 & 5.24 & -25 & 0.176 \\
\hline D5 & T6 & -0.58 & 240 & 0.32 & 1.48 & 64.24 & 0.68 & -43 & 0.315 \\
\hline D6 & T7 & -0.58 & 120 & 0.30 & 1.47 & 12.31 & 4.99 & -15 & 0.341 \\
\hline D7 & T8 & -0.60 & 240 & 0.18 & 1.45 & 29.52 & 1.93 & -16 & 0.369 \\
\hline D8 & T9 & -0.65 & 44 & 0.11 & 1.44 & 16.22 & 6.07 & -23 & 0.395 \\
\hline D8 & T10 & -0.65 & 198 & 0.11 & 1.44 & 16.22 & 6.07 & -11 & 0.345 \\
\hline D9 & T11 & -0.70 & 246 & 0.085 & 1.44 & 11.68 & 6.38 & -10 & 0.197 \\
\hline - & T12 & -0.80 & 180 & - & - & - & - & -12 & 0.080 \\
\hline
\end{tabular}

From another point of view, it is worth to note that, applying an optimized protocol for the selective potentiostatic electrodeposition of $\mathrm{Sn}-\mathrm{Pb}$ alloys, the [Sn] and $[\mathrm{Pb}]$ values in the real leaching sample can be lowered, under acceptable efficiency conditions, below $0.1 \mathrm{~g} / \mathrm{L}$ and $1.5 \mathrm{~g} / \mathrm{L}$, respectively. Interestingly, in the tested conditions, at the extremely negative $E_{W E}$ value, of $-0.8 \mathrm{~V} / \mathrm{RE}$, the deposit was, practically, absent, indicating that, at this polarization level, the entirely quantity of consumed electricity was wasted in the RHE process.

Finally, a series of images showing the obtained $\mathrm{Sn}-\mathrm{Pb}$ alloy deposits are presented in Figure 5.

For better understand the deposits morphology, they were also mineralized with aqua-regia and the resulting solutions were analyzed by ICP-AES, the obtained results being presented in Table 5. 


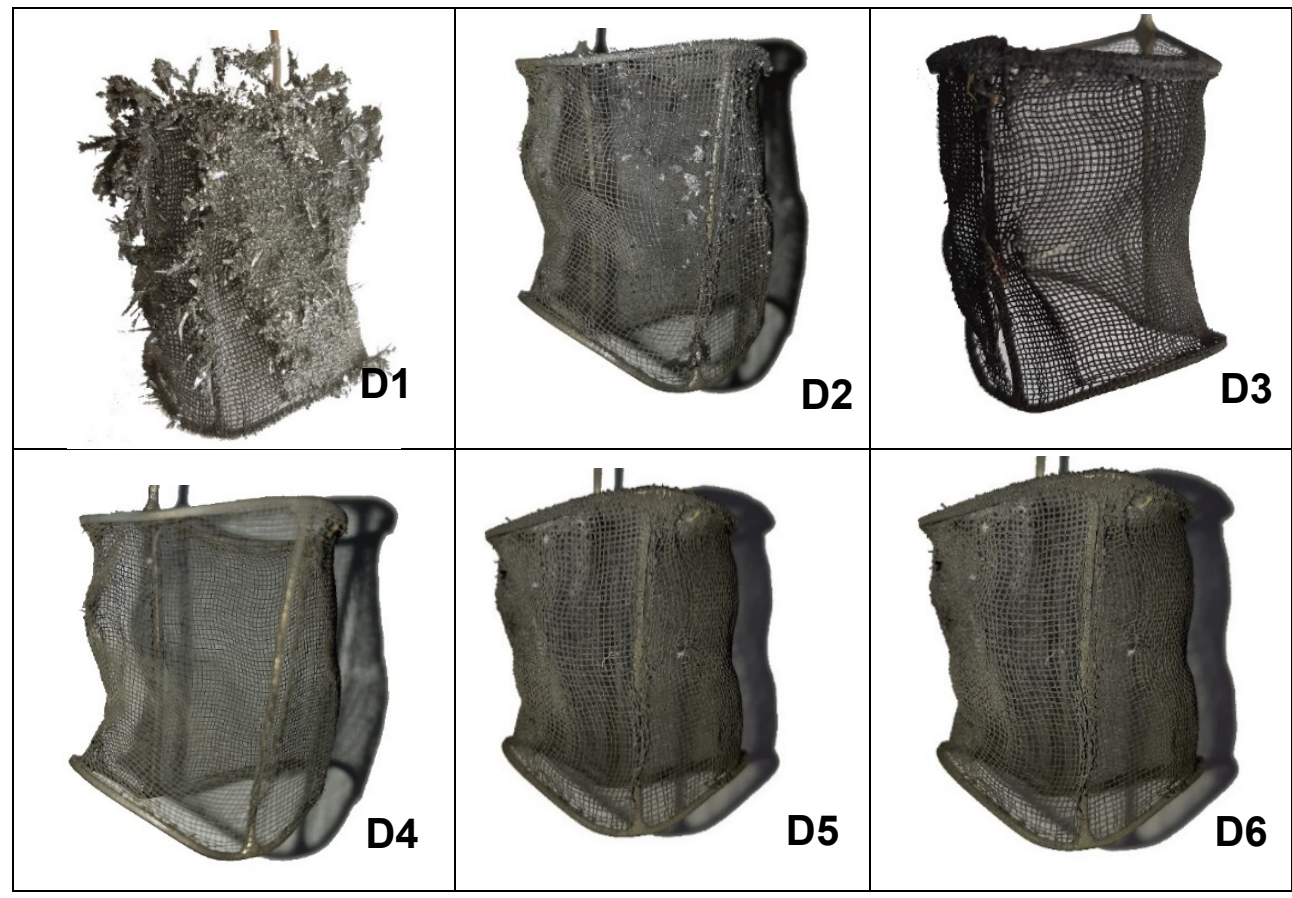

Figure 5. Images of the $\mathrm{Sn}-\mathrm{Pb}$ alloy deposits obtained by selective potentiostatic electroextraction from real leaching solutions with low $\mathrm{Cu}$ content.

Table 5. Percentage of metals (w/w) evaluated by ICP-AES in the deposits obtained by selective potentiostatic electrodeposition of $\mathrm{Sn}-\mathrm{Pb}$ alloys from the leaching solution with low $\mathrm{Cu}$ content.

\begin{tabular}{|c|c|c|c|c|c|c|c|}
\hline Deposit & $\begin{array}{c}\text { Cumulated } \\
\text { tests }\end{array}$ & $\begin{array}{c}\text { Cu } \\
\text { (\%) }\end{array}$ & $\begin{array}{c}\text { Sn } \\
\mathbf{( \% )}\end{array}$ & $\begin{array}{c}\text { Pb } \\
\mathbf{( \% )}\end{array}$ & $\begin{array}{c}\text { Fe } \\
\text { (\%) }\end{array}$ & $\begin{array}{c}\text { Ni } \\
\mathbf{( \% )}\end{array}$ & $\begin{array}{c}\text { Zn } \\
\text { (\%) }\end{array}$ \\
\hline D1 & T1 + T2 & 0.00 & 99.8 & 0.01 & 0.01 & 0.01 & 0.00 \\
\hline D2 & T3 & 0.00 & 99.1 & 0.06 & 0.15 & 0.02 & 0.09 \\
\hline D3 & T4 & 0.00 & 74.3 & 25.4 & 0.02 & 0.00 & 0.01 \\
\hline D4 & T5 & 0.01 & 49.3 & 49.7 & 0.52 & 0.02 & 0.24 \\
\hline D5 & T6 & 0.00 & 14.6 & 82.6 & 0.03 & 0.05 & 0.01 \\
\hline D6 & T7 & 0.03 & 77.3 & 20.2 & 0.26 & 0.17 & 0.55 \\
\hline D7 & T8 & 0.01 & 80.6 & 13.8 & 0.23 & 0.19 & 0.10 \\
\hline D8 & T9 + T10 & 0.01 & 85.1 & 11.6 & 0.79 & 0.91 & 0.54 \\
\hline D9 & T11 & 0.03 & 91.7 & 5.6 & 1.04 & 0.26 & 0.48 \\
\hline
\end{tabular}


Corelating the data from Table 3, Figure 5 and Table 4, it is clear that, at high [Sn] in the solution, dendritic deposits (see D1 and D2), with extremely high content of Sn were obtained. Further, simultaneously with the decrease on [Sn] and [Pb] values, the $\mathrm{Sn}-\mathrm{Pb}$ alloy deposits become smooth and compact, increasing their adherence on the cathode surface. Also, the ratio between $\mathrm{Sn}$ and $\mathrm{Pb}$ in the deposits changes significantly, depending on [Sn] and [Pb] values and the applied $E_{W E}$. Additionally, it is worth to note that the major impurities such as $\mathrm{Ni}$, Fe and $\mathrm{Zn}$, which are present in large quantities in the leaching solution and have standard reduction potentials close to the electrodeposition potentials of $\mathrm{Sn}$ and $\mathrm{Pb}$, start to be incorporated significantly into the $\mathrm{Sn}-\mathrm{Pb}$ alloy deposit only when the EWE decrease under $-0.65 \mathrm{~V} / \mathrm{RE}$

Finally, we conclude that the selective electrodeposition of $\mathrm{Sn}-\mathrm{Pb}$ alloys, in potentiostatic mode, from leaching solutions with extremely low content of $\mathrm{Cu}$, represents a feasible, efficient and cost-effective technology for the advanced recovery of $\mathrm{Sn}$ and $\mathrm{Pb}$ from WPCBs.

\section{CONCLUSIONS}

Correlating all the recorded data and the evaluated parameters during the experiments concerning the selective potentiostatic electrodeposition of $\mathrm{Cu}$ and $\mathrm{Sn}-\mathrm{Pb}$ alloys from the leaching solution based on the $\mathrm{KBr} / \mathrm{HBr} / \mathrm{Br}_{2}$ system, we concluded that the proposed and tested technologies are perfectly feasible, allowing to obtain deposits of high quality and purity, with a good commercial value, comparable with other less ecological and efficient processes cited in the literature [23].

The cost-effectiveness of the proposed processes can be assured by the rigorous monitoring and control of the main process parameters, such as the concentration of $\mathrm{Cu}, \mathrm{Sn}$ and $\mathrm{Pb}$ ions, the $\mathrm{pH}$ and ORP of the electrolyte, and the values of the imposed $E_{W E}$ and/or I WE $_{\text {parameters. }}$

In order to increase the performances of the selective potentiostatic electrodeposition of the $\mathrm{Sn}-\mathrm{Pb}$ alloys, an intermediate step of Cu cementation on metallic $\mathrm{Sn}$ must be inserted between the $\mathrm{Cu}$ electroextraction and $\mathrm{Sn}-\mathrm{Pb}$ alloys electrodeposition stages.

Following the presented protocols, final $[\mathrm{Cu}],[\mathrm{Sn}]$ and $[\mathrm{Pb}]$ values below $0.01 \mathrm{~g} / \mathrm{L}, 0.1 \mathrm{~g} / \mathrm{L}$ and $1.5 \mathrm{~g} / \mathrm{L}$, respectively, can be reached under very promising conditions of profitability. 


\section{EXPERIMENTAL SECTION}

\section{Chemicals}

Reagents as $\mathrm{KBr}$ and $\mathrm{HBr}$ are purchased by Fluka and Sigma-Aldrich and used as received.

The real leaching solution was obtained by mixing equal samples from different solutions resulted by the leaching of the exposed metals from $10 \mathrm{PC}$ motherboards in $2.2 \mathrm{~L}$ of $2 \mathrm{M} \mathrm{KBr}+0.5 \mathrm{M} \mathrm{HBr}+1 \mathrm{M} \mathrm{Br}_{2}$ solutions [21]. The ORP of the resulting mixture $(1 \mathrm{~L})$ was lowered by placing it over 2 $\mathrm{kg}$ of WPCBs, after which the solution $\mathrm{pH}$ was adjusted to 0.1 by addition of $\mathrm{HBr} 47 \%$. The concentrations of the main metallic ions in the final starting solution were: $12.89 \mathrm{~g} / \mathrm{L} \mathrm{Cu} 7.9 \mathrm{~g} / \mathrm{L} \mathrm{Sn} ; 3.97 \mathrm{~g} / \mathrm{L} \mathrm{Pb} ; 9 \mathrm{~g} / \mathrm{L} \mathrm{Zn} ; 5.6 \mathrm{~g} / \mathrm{L} \mathrm{Fe}$; $0.8 \mathrm{~g} / \mathrm{L} \mathrm{Ni}[13]$.

\section{Experimental methods}

The selective potentiostatic electrodeposition experiments of $\mathrm{Cu}$ and $\mathrm{Sn}-\mathrm{Pb}$ alloys were performed in an electrochemical reactor divided using a porous ceramic membrane. As anolyte, $0.5 \mathrm{~L}$ samples of fresh $2 \mathrm{M} \mathrm{KBr}+0.5 \mathrm{M}$ $\mathrm{HBr}$ were introduced in the anodic compartment. The cathodic compartment was filled with $0.5 \mathrm{~L}$ of mixture of real leaching solutions described in the chemicals part.

The reactor was equipped with a Fisher type electrode as WE, consisting in a cylindrical Pt mesh, with $\varnothing_{\mathrm{EXT}} \cong 25 \mathrm{~mm}$ and a height of $\cong 40 \mathrm{~mm}$, fixed on a Pt wire frame with $\varnothing=1 \mathrm{~mm}$. As CE, a rectangular graphite block with dimensions of $80 \mathrm{~mm} \times 70 \mathrm{~mm} \times 20 \mathrm{~mm}$ (height $\times$ width $\times$ thickness), was used. The WE, CE and 2 reference electrodes of $\mathrm{Ag} / \mathrm{AgCl} / \mathrm{KCl}_{\text {sat }}$ type (named further as RE) were connected to a computer controlled potentiostat (DXC236, Datronix Computer, Romania).

The measurements concerning the cementation of $\mathrm{Cu}$ on metallic $\mathrm{Sn}$ were performed in a glass cell with a volume of $400 \mathrm{~mL}$, in which were introduced $300 \mathrm{~mL}$ of solution resulting after all the tests of selective potentiostatic electroextraction of $\mathrm{Cu}$. Over this solution $26.04 \mathrm{~g}$ of soldering alloy Sn $97 \%$-Cu 3\% were added. The initial soldering alloy, with a diameter of $3 \mathrm{~mm}$, was divided into 252 pieces with a length of approx. $5 \mathrm{~mm}$, resulting an estimated grains area of approximately $120 \mathrm{~cm}^{2}$.

Additionally, 2 laboratory multi-meters (Consort C863, Consort, Belgium) were used as galvanically insulated electrochemical interfaces with high input impedance between the data acquisition board (NI6121, National Instruments, 
USA) and the $\mathrm{pH}$ and ORP sensors (SP10T and SO50X, respectively, both from Consort, Belgium). During the experiments, the electrolyte from the cathodic compartment was stirred using a magnetic stirrer (FB 15001, Fischer Scientific).

Before each test, the WE was cleaned by immersion during $10 \mathrm{~min}$. in aqua-regia, washed with double-distilled water and dried under nitrogen jet, and weighed using an analytical balance (XA110, RADWAG, Polonia).

After each experiment, the Fisher type WE was removed from the electrochemical reactor and the obtained $\mathrm{Cu}$, or $\mathrm{Sn}-\mathrm{Pb}$ alloy deposits were washed with $2 \mathrm{M} \mathrm{KBr}+0.5 \mathrm{M} \mathrm{HBr}$ mixture (to avoid the precipitation of $\mathrm{Cu}$, $\mathrm{Sn}$ and $\mathrm{Pb}$ ions), cleaned with double-distilled water and dried with pure acetone and pure nitrogen jet. Finally, the deposits were weighed using the analytical balance and detached from the electrode by mineralization with $28 \mathrm{~mL}$ of aqua-regia. The resulted solutions were analyzed by ICP-AES method, using a SPECTRO CIROS CCD spectrometer (SPECTRO Analytical Instruments, Germany). The concentrations of the dissolved metallic ions from the leaching solutions were measured by flame atomic adsorption spectroscopy (FAAS), using an AVANTA-PM spectrometer (GBC, Australia).

\section{ACKNOWLEDGMENTS}

The present work has received financial support through the project: Entrepreneurship for innovation through doctoral and postdoctoral research, POCU/380/6/13/123886 co-financed by the European Social Fund, through the Operational Program for Human Capital 2014-2020.

This work was also supported by a grant of the Romanian Ministry of Research and Innovation, CCCDI-UEFISCDI, project number PN-III-P1-1.2PCCDI-2017-0652 / 84PCCDI/2018, within PNCDI III.

\section{REFERENCES}

1. B. Li, D.-A. Pan, Y.-H. Jiang, J.-J. Tian, S.-G. Zhang, K. Zhang, Rare Metals, 2014, 33(3), 353-357.

2. A. Kumari, M. Ku. Jha, J.-C. Lee, R.P. Singh, J. Clean. Prod., 2016, 112, 48264834.

3. R.K. Nekouei, I. Tudela, F. Pahlevani, V. Sahajwalla, Curr. Opin. Green Sustain. Chem., 2020, 24, 14-20.

4. Z. Sun, H. Cao, P. Venkatesan, W. Jin, Y. Xiao, J. Sietsma, Y. Yang, Front. Chem. Sci. Eng., 2016, 11(3), 308-316. 
5. F. Moosakazemi, S. Ghassa, F. Soltani, Mo. R.T. Mohammadi, J. Hazard. Mater., 2020, 385, 121589.

6. S.-A. Dorneanu, E. Covaci, F. Imre-Lucaci, G.L. Turdean, Studia UBB Chemia, 2019, 64(2 T2), 555-565.

7. C. Cocchiara, S.-A. Dorneanu, R. Inguanta, C. Sunseri, P. Ilea, J. Clean. Prod., 2019, 230, 170-179.

8. L. Pietrelli, S. Ferro, M. Vocciante, Renew. Sust. Energ. Rev., 2019, 112, 317323.

9. S. Akbari, A. Ahmadi, Chem. Eng. Process., 2019, 142, 107584.

10. P.K. Choubey, R. Panda, M.K. Jha, J.-C. Lee, D.D. Pathak, Sep. Purif. Technol., 2015, 156, 269-275.

11. M.S.B. da Silva, R.A.C. de Melo, A.L. Lopes-Moriyama, C.P. Souza, J. Environ. Manage., 2019, 246, 410-417.

12. J.A. Barragan, C.P. de León, J.R.A. Castro, A. Peregrina-Lucano, F. GómezZamudio, E. R. Larios-Durán, ACS. Omega., 2020, 5(21), 12355-12363.

13. M.-I. Frîncu, E. Covaci, S.-A. Dorneanu, P. Ilea, Studia UBB Chemia, 2020, 65(3), 33-44.

14. W. Jin, Y. Zhang, ACS Sustain. Chem. Eng., 2020, 8(12), 4693-4707.

15. J. Yang, Y. Wu, J. Li, Hydrometallurgy, 2012, 121-124, 1-6.

16. S. Fogarasi, F. Imre-Lucaci, M. Fogarasi, A. Imre-Lucaci, J. Clean. Prod., 2019, 213, 872-883.

17. H.M. Veit, A.M. Bernardes, J.Z. Ferreira, J.A.S. Tenorio, C. de F. Malfatti, J. Hazard. Mater., 2006, 137(3), 1704-9.

18. R.S. El-Nasr, S.M. Abdelbasir, A.H. Kamel, S.S.M. Hassan, Sep. Purif. Technol., 2020, 230, 115860.

19. S. Ghosh, Thin Solid Films, 2019, 669, p. 641-658.

20. S.-A. Dorneanu, Studia UBB Chemia, 2017, 62(3), 177-186.

21. S.-A. Dorneanu, A.-A. Avram, A.-H. Mărincaş, N. Cotolan, T. Frenţiu, P. Ilea, Studia UBB Chemia, 2018, 63(4), 147-158.

22. R.M. Lamya, L. Lorenzen, J. South. Afr. Inst. Min. Metall., 2005, 21-29.

23. J. Hao, Y. Wanga, Y. Wua, F. Guo, Resour. Conserv. Recycl., 2020, 157, 104787. 